\title{
ESTUDIO DE LAS ESTRUCTURAS YUXTAPUESTAS EN EL DISCURSO ABSURDO ${ }^{1}$
}

\section{STUDY ON THE JUXTAPOSED STRUCTURES IN THE ABSURD SPEECH}

\author{
Jesús Portillo Fernández ${ }^{2}$ \\ Universidad de Sevilla, GILLIUS (España)
}

Recibido: 2-6-2015

Aceptado: 2-11-2015

Resumen. Estudio pragmático de las estructuras yuxtapuestas como posible mecanismo responsable de la comunicación absurda. Análisis del funcionamiento de los saltos y las conexiones discursivas establecidas mediante yuxtaposición, estudio del silencio y del discurso referido en la generación de contenidos implícitos absurdos. Explicación de la yuxtaposición como motor semántico responsable del enriquecimiento contextual.

Palabras clave: yuxtaposición; silencio; absurdo; inferencia; sentido discursivo.

\begin{abstract}
Pragmatic study of juxtaposed structures as possible mechanism responsible for absurd communication. Analysis of the functioning of the jumps and discursive connections caused by juxtaposition, study of silence and referred speech in the generation of absurd implicit contents. Explanation of juxtaposition as semantic engine responsible for contextual enrichment.
\end{abstract}

Keywords: juxtaposition; silence; absurd; inference; discursive sense.

[1] Artículo inscrito en la investigación "La interpretación inferencial en la comunicación absurda. (Aplicado a un programa de Matt Groening)" de la Universidad de Sevilla.

[2] (jeporfer@gmail.com) Investigador del Grupo de lógica, lenguaje e información de la Universidad de Sevilla (GILLIUS. HUM-609). Doctor en Filología y licenciado en Filosofía y Humanidades. 


\section{Una lectura pragmática de la yuxtaposición}

Nos alejamos de la concepción tradicional de las estructuras yuxtapuestas ofrecida por la gramática formal para abordar estas construcciones desde un punto de vista pragmático. Para comprender la importancia de la yuxtaposición en la comunicación absurda es necesario concebirla como un mecanismo capaz de producir contenidos implícitos, de sugerir conexiones que van más allá de la lectura literal del discurso y del ahorro de tiempo y esfuerzo en los actos comunicativos (economía lingüística). Nos referimos a un recurso sintáctico que posee la capacidad de unir enunciados y formar oraciones con sentido completo sin la necesidad de usar nexos, sólo a partir de signos de puntuación (construcciones asindéticas). Al tratarse de construcciones en las que se hacen suceder elementos sin que en la elocución haya ningún nexo gramatical, distinguimos por un lado oraciones compuestas en las que la pausa y la entonación marcan la unidad semántica con la que se han expresado y por otro oraciones independientes. El rasgo fónico que define a las oraciones yuxtapuestas es el descenso de la entonación en cada una de las unidades que la forman.

Desde el punto de vista del significado, las oraciones yuxtapuestas pueden tener distintos valores, ya que o bien tienen valor de coordinación (se encuentran al mismo nivel sintáctico), o bien tienen un valor de subordinación (una oración depende de la otra). (Gómez, 2005: 180).

Sin embargo, nosotros nos detendremos en analizar la potencialidad semántica de la yuxtaposición con el objetivo de mostrar las propiedades y capacidades de este recurso para crear significados (incluidos los absurdos).

Las oraciones construidas por yuxtaposición establecen las relaciones de significado a partir de la adyacencia de los elementos. Esto hace que el receptor del mensaje necesite buscar una explicación que justifique tal adyacencia. El oyente debe inferir las relaciones que aparecen de forma implícita para acceder a la comprensión del contenido implícito subyacente en el mensaje. Este tipo de relación paratáctica enlaza elementos mediante una breve pausa, lapso en el que se activa en el receptor la necesidad de encontrar la razón por la que el emisor colocó consecutivamente los enunciados. Establece secuencias entre los elementos que integran el mensaje, al tiempo que focaliza la atención a través de diversos medios: mediante enumeraciones o contrastes, por acumulación, a partir de secuencias temporales o locales, etc. Establece jerarquías mediante relaciones de contigüidad y deja abierto el conjunto de interpretaciones que el receptor-lector pueda hacer, ya que no muestra explícitamente la intención comunicativa del mensaje. La yuxtaposición es un recurso polivalente, capaz de tender puentes semánticos y discursivos entre las ideas expuestas en los

Thémata. Revista de Filosofía №53 (2016) pp.: 237-260. 
enunciados y transmitir indirectamente el sentido de estos. Genera relaciones subordinadas o lineales basadas en los acuerdos tácitos (topoi) entre los interlocutores, la complicidad social que hace posible la codificación y la descodificación del mensaje en el mismo sentido. Se trata de un procedimiento pregramatical o agramatical capaz de unir oraciones, una unidad oracional entonatoria e ideológica.

\section{Yuxtaposición: saltos y conexiones discursivas}

Como hemos dicho antes, la adyacencia de enunciados produce en el receptor del mensaje la necesidad de buscar la relación que dote de significado a la oración completa. La suma de significado de las proposiciones yuxtapuestas puede comportarse de múltiples formas como veremos más adelante, estableciendo otro tipo de relaciones paratácticas (oraciones coordinadas) y relaciones hipotácticas (oraciones subordinadas). La yuxtaposición pone en funcionamiento una especie de proceso de empatía con el emisor, tratando de averiguar las razones que le han llevado a emitir juntos enunciados que en principio no guardan relación alguna. Si cumplimos con el «principio de relevancia» de Grice debemos hacer que nuestra contribución sea lo más informativa posible, pero no excesivamente informativa (máxima de cantidad); no debemos mentir o decir algo de lo que no tengamos pruebas para demostrarlo (máxima de cualidad), debemos transmitir información relevante (máxima de relación), así como ser breve, ordenado, evitar expresiones oscuras y no ser ambiguo (máxima de modalidad). Al comunicarnos pretendemos activar la estructura mental pertinente al contenido que le vamos a transmitir, considerando por tanto la contextualización como un proceso inferencial.

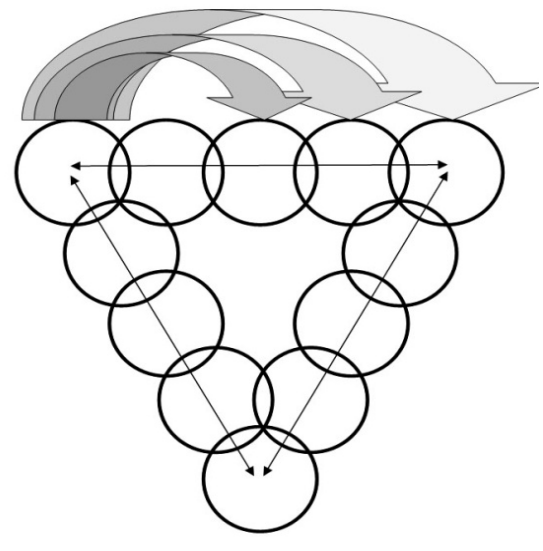

Diagrama de flujo de las conexiones entre ideas

Figura 1

Thémata. Revista de Filosofía $\mathrm{N}^{\circ} 53$ (2016) pp.: 237-260. 
Si partimos de la idea de que la mente nunca está vacía y que siempre manejamos información en diferentes estados mentales, podemos afirmar que ninguna idea se elabora en nuestra mente de forma aislada, sino que estamos siempre en contacto con otras ideas, propias o ajenas. Una parte considerable de la información que codificamos la destinamos a guiar la interpretación que tiene que seguir nuestro auditorio, ahorrando esfuerzos en el proceso de contextualización y facilitando la construcción del contexto donde debe ser interpretada la información transmitida. Las experiencias, los conocimientos y las opiniones como una amalgama interactiva y ordenada que establecen conexiones léxicas, semánticas, pragmáticas, lógicas, etc. El pensamiento está interconectado, lo que nos permite transitar rápidamente de una idea a otra, a veces tan rápido que perdemos el origen de la reflexión al llegar a término.

Dando el paso hacia el lenguaje, debemos hablar del lexicón mental ${ }^{3}$ o competencia léxica, el conocimiento que un hablante tiene interiorizado del vocabulario. El lexicón mental es parcial en relación con el vocabulario de determinada comunidad hablante; es decir, a diferencia del vocabulario común resultado de un conocimiento compartido y supraindividual (recogido en gran parte por los diccionarios), el lexicón es individual. Las unidades del lexicón establecen relaciones semánticas (significado, tema, relaciones paradigmáticas, etc.), discursivas (frecuencia, tipo de texto, registro, etc.), morfológicas (prefijos, sufijos, regularidades, irregularidades, etc.), gráficas (patrones gráficos, normas, etc.), fónicas (sonido, número de sílabas, patrón acentual, etc.) e incluso de carácter no lingüístico (imágenes visuales, auditivas, conocimiento del mundo, conocimientos culturales, etc.). El lexicón es dinámico y el conocimiento es incrementable porque los distintos inputs proporcionan información variada que contribuye a ampliar el conocimiento que se tiene sobre las distintas unidades.

Dejando a un lado la importantísima faceta del aprendizaje para centrarnos en el uso de la yuxtaposición como comodín pragmático, reparamos en el esfuerzo lingüístico-cognitivo que supone la transmisión del pensamiento. Nos referimos con «comodín pragmático» a la capacidad de este mecanismo de combinar elementos de diversas formas y dar lugar a contenidos implícitos necesarios para extraer el sentido de los enunciados. Nos preguntamos por la transmisión interlocutiva de la información yendo más allá de las relaciones internas y dinámicas establecidas en el lexicón mental. Cueto (2002: 87) explicaba que «se confía en la habilidad del emisor para reproducir el pensamiento del receptor que a su vez primeramente tuvo que imaginarse la mente del destinatario». Resulta inte-

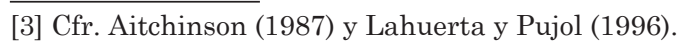

Thémata. Revista de Filosofía No53 (2016) pp.: 237-260. 
resante estudiar el flujo de comunicación lingüística para comprender la yuxtaposición y los procesos mentales que generan.

En el intercambio comunicativo tanto el hablante como el oyente llevan a cabo un acto de confianza ciega a partir de supuestos sobre el estado mental del otro que permite transmitir la información. Es el entorno cognitivo de una persona el conjunto de supuestos al que accede otra para comunicarse de forma fluida, solo rectificado en caso de interpretación errónea. La importancia de integrar la información recibida en un estado mental desconocido se basa en la confianza de que el otro va a interpretar las palabras en el mismo sentido en el que el emisor las dice. Fueron Sperber y Wilson (1986) los primeros en plantear hipótesis del conocimiento mutuo, una idea que concibe el subconjunto de supuestos que el oyente tiene sobre el mundo. Se trata de una construcción psicológica que abarca la información que tenemos sobre nuestro entorno físico, los enunciados precedentes, las creencias, las expectativas, las hipótesis, las anécdotas o cualquier elemento que influya en la interpretación.

\section{Homer: Déjame ayudarte hijo}

Bart: Sería ridículo

Homer: Esto no marcha / es terco // Espera un segundo (leyendo) Primera ley Cosby de perversidad intergeneracional / no importa lo que usted le pida a su hijo / él hará siempre lo contrario

[T3C9-1]

En este ejemplo, el protagonista lee la denominada primera ley Cosby de perversidad intergeneracional formulada con una oración yuxtapuesta: no importa lo que usted le pida a su hijo, él hará siempre lo contrario. De estas dos proposiciones inferimos la existencia de un conflicto entre padres e hijos en el que los segundos actúan de forma contraria a los primeros para afirmarse. Extraemos la idea de que los hijos interpretan las peticiones de los padres como imperativos y que por esta razón deben ser rechazados o contrariados. Y en tercer lugar, pero en este caso más importante que los dos anteriores, podemos deducir que para que el hijo haga lo que él quiere, el padre debe pedirle lo contrario.

La mente humana tiene la capacidad integradora suficiente para contextualizar la información recibida (lo dicho por el emisor) a partir de sugerencias, atribuyendo al interlocutor objetivos e intenciones comunicativas de las que no tiene certeza. La información remática (nueva) se pone en relación con la información temática (ya conocida), dando lugar inferencias entre las ideas y estableciendo relaciones revisables como un 
continuo relevante para nosotros. Maximizar la relevancia de la información procesada es el objetivo cognitivo del proceso.

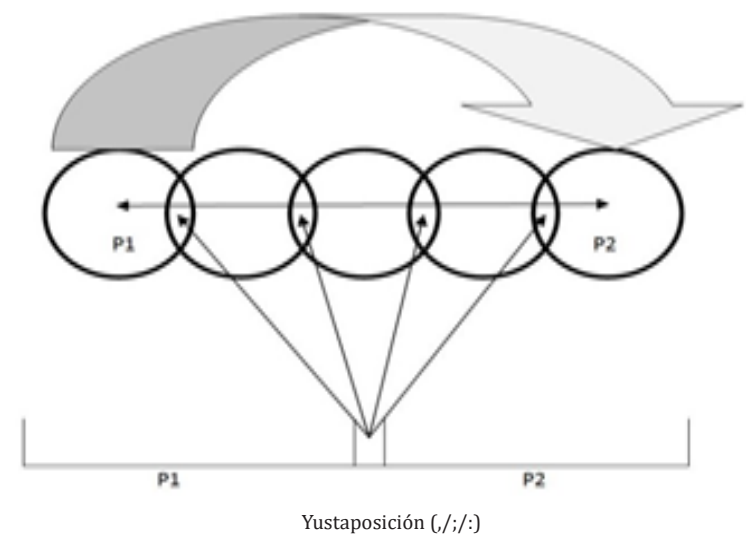

Figura 2

Los resultados inferidos del discurso yuxtapuesto ponen en juego los conocimientos previos de los interlocutores, la información aportada por el mensaje y la posibilidad de generar información novedosa. El quid reside en la capacidad de adivinar por partida doble lo que (probablemente) piensa nuestro interlocutor como elección más obvia y de ese modo intuir lo que él piensa que nosotros pensamos que piensa.

Homer: Estúpido Moe / cabezón siniestro / ladrón de recetas / caraculo Marge: Bueno Homer / tal vez te consuele el hecho de saber que algo creado por ti está haciendo feliz a tanta gente $\S$

Homer: $\quad \S$ iUpppp! // ¡Mírame! Estoy haciendo feliz a la gente // ¿Qué bien / soy un hombre mágico! / Del país feliz / de la casa de la gominola de la calle de la piruletaaaaaaa!

[T3C10-1]

Por ejemplo, en este caso, en la segunda intervención del protagonista encontramos una muestra de discurso irónico. La yuxtaposición de cinco enunciados que expresan alegría en una situación de enfado nos pone sobre la pista al necesitar una interpretación que parta del contenido implícito inferido, en concreto, de las múltiples imágenes procedentes de cuentos infantiles que utiliza para enfatizar irónicamente sus emociones. La interpretación de enunciados yuxtapuestos requiere de información 
nueva, bien extraída del mismo discurso o bien implementada a partir del acervo teórico del receptor. La yuxtaposición, explicada con términos de Brown y Yule (1983), es un productor remático que parte de la inferencia. Un modo de generar información nueva mediante ostensiones implícitas por yuxtaposición, es la enumeración de datos de diferentes etapas cronológicas de un mismo objeto de estudio. De este modo se consigue a partir de enunciados contrastivos inferir información nueva que ponga de relieve las conclusiones de las operaciones adversativas que propician las premisas de las que se parte. Al igual que todos los sistemas lógicos, los sistemas de planificación son asimétricos, es decir, no es una simple retro-construcción del plan intencional del hablante. Esto se debe a que desde una misma conclusión podríamos llegar a infinitas premisas, al igual que número indefinido de planes podrían converger en un único enunciado.

La interpretación o contextualización del oyente es la que integra la información recibida, reconstruyendo los vínculos implícitos de cualquier índole establecidos por el emisor. El emisor puede condicionar u orientar el contexto interpretativo, aunque no lo determine completamente, ya que puede recrear una realidad mental que logre instalarse satisfactoriamente en la mente del otro. El hecho de que el emisor intervenga en la restricción contextual del contenido afectará al modo en que el receptor interprete la información recibida. Los enunciados yuxtapuestos, como mecanismos capaces de producir nuevos contenidos y sentidos, son utilizados por el locutor absurdo para concitar distintas voces (inclusión discursiva y polifonía) y mezclar ideas congruentes en la misma conversación a partir del discurso referido. Con el objetivo de entender el funcionamiento de la yuxtaposición en el absurdo, expondremos en primer lugar las bondades y riesgos de este recurso sintáctico en la construcción del discurso: discurso referido y silencios.

\section{Yuxtaposición y discurso referido}

El discurso yuxtapuesto constituye una valiosa herramienta a la hora de agrupar, asimilar y citar palabras ajenas con diversos grados de implicación y aceptación. Estas estructuras sintácticas nos permiten desgajar la deixis espacio-temporal del acto del habla mediante la relación de la cita directa y el marco contextual. Los segmentos establecidos en el lenguaje oral con la pausa distinguen la autonomía de las proposiciones y reconocen la relación de suplemento y/o complemento entre los elementos relacionados. La yuxtaposición entre enunciados genera nuevos significados y la posibilidad de intervención de diversas voces en el discurso como en el siguiente ejemplo. 
Homer: ¡Deja que me ocupe yo Marge / esto me lo sé de memoria! / Me gustas como amigo / deberíamos salir con otras personas / no hablas mi idioma

[T4C15-2]

Es posible la disociación de los sujetos del discurso al presentar correferencias diversas. El discurso es heterogéneo y polifónico al arrastrar los valores de las palabras usadas. Sin embargo, es decisivo el modo en que son presentadas linealmente en el tiempo esas ideas. Construir mensajes mediante yuxtaposición supone otorgar un hilo discursivo a los elementos concitados con el objetivo de conformar una interpretación no unívoca, un mensaje abierto. Los enunciados yuxtapuestos permiten un variado elenco de interpretaciones, desde la manipulación malintencionada de la información transmitida hasta el guiño del humor absurdo. La yuxtaposición ha sido entendida por muchos autores como una variedad de oraciones coordinadas que no expresan gramaticalmente la relación entre las proposiciones que forman el sentido discursivo global del mensaje. Distinguimos en las construcciones yuxtapuestas el modus (intención del hablante) y el dictum (estructura sintáctica) asindéticos, funcionando la entonación como elemento encargado de fragmentar la comunicación.

$\mathrm{Al}$ encontrar el marco contextual de una cita debemos comprender que el emisor puede asumir el contenido de las palabras de las que se hace eco o no, ya que a veces expone su punto de vista subjetivo y otras veces no. Todos los discursos hacen referencia al momento del decir, pueden tener diversos valores (presentación de una cita como argumento, como ejemplo oportuno en una declaración, como caso utilizado para distanciarse de lo dicho, etc.) y propician ostensiones e inferencias. La neutralidad intencional causada por la ausencia de nexos implica propuestas interpretativas, sin orientar la interpretación del receptor. Cuando utilizamos una cita directa insertamos un enunciado de otro discurso en la enunciación de la reproducción, es decir, cortamos, usamos y respetamos la deixis utilizando comillas. Por ejemplo, en el siguiente caso el protagonista enumera tres frases cortas como consejo a su hijo utilizando la cita directa. Al reproducir las palabras del mismo modo en que fueron dichas en su momento, suceden dos cosas: conservan las coordenadas es- 
pacio-temporales y exigen un contexto interpretativo similar al de origen para que estas tengan sentido.

Homer: No hay tiempo para eso / tengo mil cosas importantes que hacer (coge su lista y lee: tener charla de hombre a hombre con Bart) // ¡Ven aquí!

Bart: ¡Ay qué corchos! (Bart se pone encima de las piernas de Homer con las nalgas al aire creyendo que le iba a pegar)

Homer: ¡No! / Solo quiero hablar de corazón a corazón // ¿Sabes Bart? Después de mí eres el único hombre de este hogar y eso significa (1s $\downarrow$ ) Bart: ¡Venga! - ¡que yo hago un montón de cosas! ¡Lisa es la que no levanta ni chapa / grítale a ella!

Homer: ¡CÁLLATE! BART! / si te va a gustar $\downarrow$ / quiero compartir algo contigo // Las tres frases cortas que sacarán tu vida adelante // La primera: "no digas que he sido yo" // la segunda / "uh / ¡buena idea jefe!" y la tercera / "estaba así cuando llegué"

[T2C11-5]

Las estructuras yuxtapuestas exigen la búsqueda del sentido comunicativo, requieren el hallazgo de la relevancia de los enunciados (tanto en su relación, como con el discurso dicho en general). El orden de aparición de las proposiciones yuxtapuestas es esencial a la hora de inferir las intenciones comunicativas del emisor. Para discernir si el uso de las estructuras yuxtapuestas es un fenómeno intencionado, debemos tener amplios conocimientos sobre todos los elementos concitados en el mensaje, ya que la intencionalidad del discurso solo la conoce realmente el emisor (siendo solo accesible a partir de las implicaturas inferidas). Los ejemplos más comunes los encontramos en las ironías, en las que no podemos afirmar con total certeza la existencia de resultados inesperados o planificación del discurso. Quizás, el elemento más determinante en el proceso de producción / orientación que lleva a cabo el emisor al comunicarse es la prosodia. Por ejemplo, es muy difícil simular una interrupción en el discurso sin que la última oración pronunciada termine con una cadencia. Las pausas intercaladas en las proposiciones yuxtapuestas reflejan la estructuración previa de las ideas, mientras que en las interrupciones el cese del discurso tiene lugar como un corte en la uniformidad de la entonación. Podemos hacer calas (pausas reflexivas), calibrar la importancia de cada enunciado en particular e inferir el sentido supraoracional del mensaje. Cuando hablamos de sentidos inferidos a partir de los contenidos implí- 
citos subyacentes a enunciados yuxtapuestos, hablamos de organización textual, no de organización oracional.

\section{Yuxtaposición y silencio}

El recurso paratáctico que tratamos ofrece a partir de pausas silencio que rompe el continuo de la comunicación, quizá la clave de la yuxtaposición a la hora de generar nuevos significados. Los enunciados yuxtapuestos adquieren su sentido como oración compuesta mediante el esfuerzo de recomposición que lleva a cabo el receptor, reconstruyendo la intencionalidad discursiva del emisor. La adyacencia de las proposiciones yuxtapuestas puede estar mediada por una demora, un silencio que se alarga brevemente en la elocución. La demora puede ser entendida como el énfasis silencioso de lo implícito, una manera tácita de hacer hincapié en los significantes yuxtapuestos de las proposiciones con el objetivo de transmitir el significado implícito en la oración. El silencio es, después de la palabra, el segundo instrumento de comunicación, capaz en ocasiones de transmitir información de forma equivalente a ésta. Desde principios del siglo XX se intensificó el interés por el silencio en disciplinas como la lingüística o la sociología. Se ha intentado ofrecer por parte de especialistas en la materia clasificaciones sobre los tipos de silencio y las funciones que desempeñan en la comunicación. Repasamos algunas de las más importantes para comprender mejor la relación entre la yuxtaposición, el silencio y el sentido discursivo.

Jensen (1973) al estudiar el silencio distinguía cinco funciones prototípicas, funciones a su vez divididas en una parte negativa y otra positiva:

- Hablaba del silencio como conector (función de conexión) capaz de unir o desunir a las personas.

- Una función de afectación donde el silencio indica hostilidad, odio, indiferencia, aceptación o respeto.

- Una función de revelación, ligada a la ocultación o revelación de información donde el silencio funciona como llenado de la omisión o elemento enfático de ésta.

- Una función de evaluación con la que el silencio permite indicar disentimiento o asentimiento en relación con el discurso en el que se dé.

- Por último y quizás la más interesante, una quinta función de actividad. Jensen subdividía la función de actividad en tres subfunciones: 
- Las pausas que anteceden al discurso (actitud reflexiva antes de hablar).

- El silencio como ausencia de actividad mental, es decir, cuando el silencio llena los momentos en los que el personaje no piensa nada.

- El silencio como ausencia de actividad; dicho de otro modo, cuando el silencio llena los momentos en los que el persona no interacciones verbalmente con nadie.

El mismo año, Bruneau (1973) publicaba un artículo sobre el silencio en el que distinguía tres tipos: silencios socioculturales, silencios interactivos y silencios psicolingüísticos. El silencio sociocultural haría referencia a las diferentes concepciones de cada cultura y al bagaje semántico incorporado en cada caso. El silencio interactivo es el producido en el transcurso de una conversación al expresar emociones, tomar decisiones, ejercer el control, etc. Y el silencio psicolingüístico abarcaría los momentos de indecisión o duda. Bruneau distinguía entre silencios lentos / largos («silencios mentales obligatorios estrechamente asociados a los procesos semánticos de descodificación del lenguaje») y silencios rápidos / cortos (propios de linealidad del lenguaje, menores de dos segundos y necesarios para la construcción gramatical del mensaje). Especialmente nos interesaremos en los silencios lentos y largos, no solo por estar asociados a la descodificación semántica del lenguaje sino por su declarada intencionalidad implícita. La yuxtaposición al demorar la unión entre proposiciones implementa semánticamente la unión de los enunciados, siendo significativo el silencio en la contextualización del discurso.

A mediados de los 80 la lingüista Saville-Troike (1985: 16) presentaba una catalogación del silencio atendiendo a los dominios en los que se utiliza. Diferenciaba entre el silencio individual [interactivos (psicológico, lingüístico y sociocultural) y no interactivos (inactivo y contemplativo)], el silencio determinado por el grupo (simbólico, situacional y normativo) y el silencio institucional (rituales, religiosos, jerárquicos, etc.). Al acercarnos al silencio desde la yuxtaposición descubrimos que el mutismo interactivo no separa el contenido explícito de las proposiciones sino que las une y enriquece mediante un espacio significante que se revela en la descodificación del mensaje adecuadamente contextualizado. Una década más tarde el sociólogo Laín (1994: 461-465) volvía a retomar la denominación de Jensen sobre el silencio positivo y silencio negativo. Esta vez Laín diferenciaba los silencios positivos como los producidos al no saber qué decir 
o causados por la mudez patológica y los silencios negativos subdivididos en tres tipos:

- Silencio transignificativo. Funciona como «signo de abismamiento» y se utiliza ante la imposibilidad de decir lo que se siente.

- Silencio significativo. Utilizado para decir algo.

- Silencio presignificativo. Funciona como «suelo» de la palabra.

Solo un año antes Jaworski (1993) desde un enfoque funcional centrado en explicar el modo de manifestarse el silencio menciona la relación entre el habla y el silencio como un continuum de formas prototípicas («nonessentialist approach»). Sin embargo, la tesis de la positividad y de la negatividad del silencio llega hasta los estudios de Poyatos (1994: 178-180) a mediados de los noventa. Este autor habla del silencio «rapport» (expresión de sentimientos recíprocos), silencio natural del medio ambiente o silencio profesional como variantes del silencio positivo. Del otro lado, del silencio negativo, distingue el silencio manipulativo (en el que la duración es proporcional a la angustia causada en el interlocutor) o el silencio para expresar actitudes negativas (mutismo selectivo o situacional). Cestero (1999: 35) diferenciaba entre pausas (entre 0 y 1 segundo de ausencia de habla) y silencios (de más de 1 segundo). Explica que la mayoría de las pausas son involuntarias, mientras que los silencios son forzados, siendo el espacio más fecundo de comunicación no verbal. La importancia del silencio en la comunicación, estudiada en profundidad por Mateu (2001) en su tesis y sintetizada por Rivas (2009), pone de manifiesto que la comunicación no verbal está presente de manera permanente con la indispensable presencia del silencio. «El silencio enriquece como un espacio necesario para el desarrollo de la comunicación no verbal y por lo tanto, realiza una actividad integradora de primer orden», Rivas (2009: 106).

Precisamente en dicha actividad integradora y transmisora del contenido implícito y no verbal es en la que nos detendremos en nuestro estudio de la yuxtaposición y el silencio. Si analizamos la estructura sintáctica del discurso yuxtapuesto nos damos cuenta de que el silencio da cabida a la reflexión necesaria en la conversación sobre el significante y su significado en la segunda proposición (adyacente a la primera). 


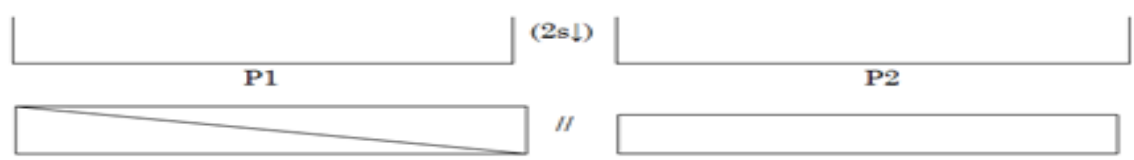

El silencio funciona como resorte que indica la necesidad inferencial del emisor. Habitualmente la cadencia fónica del término de la primera proposición enunciada antecede a la demora. Esta demora marcada funciona como gatillo o activador del contenido implícito necesario para ser capaz de unir las proposiciones con sentido. El silencio forzado (independiente de las necesidades respiratorias del hablante y de las pausas gramaticales naturales que comentábamos con anterioridad) puede establecer relaciones enfáticas o relaciones atenuantes entre los contenidos relacionados por yuxtaposición. Después de haber entendido el silencio a partir de bibliografía especializada influyente al respecto, repararemos en el absurdo ocasionado por la yuxtaposición y por el silencio. La polivalencia de la yuxtaposición puede crear discursos polifónicos, transmitir de forma eficiente gran cantidad de información mediante recursos implícitos, transgredir la linealidad del lenguaje explícito y utilizar el silencio como relleno semántico que enriquece el lenguaje no verbal. La yuxtaposición además de suponer un ahorro lingüístico considerable proporciona la oportunidad de sugerir indirectamente. La ostensión indirecta, que requiere un esfuerzo interpretativo por parte del receptor, se ve intensificada con la demora conversacional, con una pausa lo suficientemente significativa para dejar hueco a la reflexión del interlocutor. La yuxtaposición demorada puede ser considerada también como un ardid semántico para ganar tiempo en la conversación. La improvisación y la invención de argumentos pueden requerir de un leve lapso temporal, el tiempo suficiente para «salir del paso», trazar una línea tangente en una conversación que no interesa o lanzar evasivas. El carácter no planificado de la oralidad ${ }^{4}$ es el caldo de cultivo perfecto para la composición de discursos yuxtapuestos, que no requieren de una estructura sintáctica rígida mediada por nexos proposicionales.

Podemos realizar citaciones directas a partir de la yuxtaposición originando con ello un punto de inflexión y vinculación entre dos o más momentos y circunstancias. En la cita siempre se produce el contraste del universo de citación y el del contexto de reproducción, un cambio de sujeto al que atribuimos las palabras, redirección del discurso a un auditorio

[4] Cfr. Narbona (2000), Álvarez (2001) y Narbona (2001).

Thémata. Revista de Filosofía Nº53 (2016) pp.: 237-260. 
diferente del de la cita y a veces la integración de la cita directa en la estructura sintáctica del marco contextual, como en el ejemplo anterior a modo de aclaración sobre el consenso en los temas del estado. Sintácticamente la cita directa, marcada gráficamente puede adoptar muchos valores dependiendo de la situación que ocupe en el texto, complemento directo, complemento circunstancial, atributo, etc. La cita directa preserva lo ajeno en su autenticidad, personalizándolo mediante elementos léxicos que limitan la penetración del discurso citado, a pesar de poderse producir la contaminación. La concepción del presente como una instantánea que manejamos con laxitud también aparece patente en la yuxtaposición, en la que las coordenadas temporales se ven relativizadas al no contar con nexos que secuencien de manera exacta el tiempo. El uso de la yuxtaposición de citas directas concatenadas con el cuerpo principal del texto genera nuevos significados a la hora de comprender el sentido de lo comunicado. En este ejemplo anterior podemos descubrir otro valor expresivo de la yuxtaposición, su capacidad de simulación. Emular de forma paralela al relato del periodista la entrevista es lo que sucede en este caso. Aparecen yuxtapuestas respuestas que el artista dio al periodista, contextualizadas no por las preguntas expresadas explícitamente sino por la descripción del personaje por parte del redactor. Por otro lado, como ilustración del potencial del recurso que estudiamos, la elasticidad de la yuxtaposición permite insertar islotes parentéticos en diversos sitios del mensaje, posibilitando integrar datos que deben descubrirse de forma simultánea sin perder el hilo conductor.

Lenny: ¡Ay! Pero si contratan a una mujer ya no podremos escupir en el suelo

Carl: Ni quitarnos los pantalones cuando haga calor

Homer: Ni volver a mear en la fuente de agua (4s) en el caso de que // quisiéramos / no es que lo haya hecho

[T5C9-1]

La ambigüedad generada por las relaciones yuxtapuestas es rentable para el lenguaje y quizá sea esta propiedad la que le ha hecho subsistir a lo largo del desarrollo de las lenguas. Por ambigüedad consideramos que puede entenderse de varios modos o admitir distintas interpretaciones y dar, por consiguiente, motivo a dudas, incertidumbre o confusión. Sin embargo, la yuxtaposición es una «apertura semántica» basada en la polisemia y en la indefinición, construcción sintáctica polivalente en distintos contextos. En el ejemplo que acabamos de leer los cuatro segundos de silencio constituyen un exceso silencioso que delata el comportamiento incivili-

Thémata. Revista de Filosofía №53 (2016) pp.: 237-260. 
zado del personaje, tras el cual intenta fingir de manera nada exitosa que se trata de un supuesto. La interpretación inferencial del absurdo deja al descubierto la declaración sincera de intenciones del protagonista en una situación en la que la que las condiciones de salubridad funcionan como límites del comportamiento anecdótico. En otros casos es la propia demora discursiva el elemento que establece relaciones yuxtapuestas donde no las hay. En el siguiente caso el silencio forzado refuerza el contrasentido de intentar aliviar la pena de su hijo por la muerte de su payaso favorito mediante la cruda puesta en conocimiento de la evanescencia de la vida.

Homer: (se acerca a Bart para consolarle) No dejes que la muerte de Krusty te deprima / piensa que la gente muere // (da un chasquido con los dedos) constantemente // Tú mismo podrías aparecer muerto mañana (3s) // Hala / ia dormir!

[T7C15-2]

Efectivamente, a partir de la yuxtaposición de enunciados separados por un breve silencio podemos introducir en la conversación silencios significativos, utilizados para introducir nuevos significados en el discurso. Si analizamos la duración de las pausas descubrimos que los primeros enunciados están separados por una pausa inferior al medio segundo, representada en el sistema de transcripción del grupo Val.Es.Co. con una barra lateral (/). La duración de las dos siguientes pausas se sitúa entre el medio segundo y el segundo completo mientras que la tercera pausa, más larga (3s), introduce una cuña de silencio necesaria para hacer una llamada de atención al interlocutor y a los espectadores. La comunidad hablante entiende inmediatamente que es completamente absurdo mostrar una reflexión sobre la fugacidad de la vida y la presencia de la muerte a un niño de 10 años asustado antes de acostarse. La yuxtaposición de un segundo enunciado supondría añadir información que conduciría a la reinterpretación de lo anterior. El primer enunciado de una construcción yuxtapuesta tiene sentido por sí mismo y al añadirle el segundo, el primero perdería parte de su sentido debido a la incompatibilidad de algún dato.

\section{Yuxtaposición y absurdo}

La combinación de enunciados yuxtapuestos distanciados por silencios es una herramienta muy utilizada en la generación de mensajes absurdos. ¿Cómo funcionan la yuxtaposición y el silencio en el discurso absurdo? Las estructuras yuxtapuestas, la mera adyacencia de proposiciones, se ven enfatizadas a través del silencio en la ostensión de contenidos 
implícitos. Estos contenidos pueden ser utilizados para crear situaciones y discursos absurdos, motivo por el cual analizamos las relaciones paratácticas sin nexo. Recapitulemos las ideas centrales expuestas con anterioridad sobre la yuxtaposición antes de analizar las funciones pragmáticas en el absurdo:

- Supone un ahorro lingüístico considerable (costeado por la interpretación de contenidos implícitos).

- Desde un punto de vista estructural, confiere fluidez, dinamismo, apasionamiento o empaque al discurso.

- Desde un punto de vista explícito establece vinculaciones neutras que enriquecen interpretativamente el discurso.

- Constituye una invitación interpretativa hacia la implicación $(\rightarrow)$.

- Supone una estructuración previa del pensamiento.

- Es capaz de establecer saltos discursivos en un flujo de pensamiento.

- Su interpretación requiere de la reconstrucción de las conexiones mentales.

- Forma un hilo conductor discursivo no unívoco (abierto a diferentes interpretaciones).

- Permite citar y crear enunciados polifónicos.

El absurdo, íntimamente ligado con la descontextualización parcial o total del mensaje, nos sitúa frente a una situación de la que no tenemos localizadas sus referencias. La más o menos estrecha pausa que hay entre dos enunciados yuxtapuestos contiene el recorrido mental del emisor entre las ideas, un puñado de relaciones implícitas en el mensaje que habitualmente no comparten el mismo marco contextual. El receptor al intentar comprender el mensaje debe rehacer el camino y considerar las implicaciones lógicas y/o pragmáticas que el emisor haya podido realizar en su razonamiento. El humor, ligado frecuentemente a lo absurdo, aprovecha la distancia entre las proposiciones yuxtapuestas para poner al receptor delante de situaciones que no tendrían cabida en un razonamiento o argumentación lineal.

Comenzaremos analizando un ejemplo en el que la yuxtaposición formó un hilo conductor discursivo no unívoco que está abierto a diferentes interpretaciones, característica que origina el absurdo y el humorismo. 
Marge: Bueno ahora que habéis hecho las paces voy a recoger la mesa Adil: No / no señora Simpson / ya la han explotado suficientemente / hoy yo recogeré la mesa

Marge: Oh / como quieras

Homer: ¿Has visto eso? / Sabes Marge / así es como siempre deseé que nos fueran las cosas // Hemos pasado a ser una unidad familiar plenamente unida // Todos nos culpábamos / ahora ya sabemos qué pieza es la que no funcionaba

Marge: ¡Homer!

[T1C11-4]

El contexto discursivo en el que se desarrolla la conversación que acabamos de leer tiene lugar en un período de tiempo en el que Bart, el hijo mayor de la familia Simpson, está de intercambio en el extranjero y en su lugar han traído a un niño ruso. El protagonista afirma: «Hemos pasado a ser una unidad familiar plenamente unida // Todos nos culpábamos / ahora ya sabemos qué pieza es la que no funcionaba». Los dos últimos enunciados aparecen yuxtapuestos mediante una breve pausa, una pausa reflexiva que proporciona al espectador un tiempo extra para hacer su interpretación. El contenido implícito que podemos extraer partiendo desde el punto de vista del protagonista sería que el hijo mayor es el obstáculo que impide ser una familia unida a los Simpson. El humorismo absurdo nace de la conjugación de esta implicatura y el conocimiento que los espectadores tienen del protagonista (hombre de mediana edad, vago, problemático, envidioso, metepatas, etcétera). La comprensión de enunciados yuxtapuestos requiere del esfuerzo reconstructivo de las conexiones mentales que lleva a cabo el emisor antes de hablar. Del mismo modo que la yuxtaposición es un mecanismo inferencial que supone un ahorro lingüístico considerable, ofrece la posibilidad de oponer ideas sin la ayuda de nexos.

En el siguiente caso, el protagonista recibe en su casa al jefe de la central nuclear para el que trabaja (el Sr. Burns), con motivo de una campaña electoral a favor de este, al presentarse como candidato a la alcaldía de la ciudad. El perro de los Simpson se precipita sobre el jefe y lo tumba en el suelo delante de todas las cámaras de televisión. En ese momento el protagonista exclama «Perro malo!» y acto seguido dándose cuenta del error de no haber controlado al perro, improvisa y tras una breve pausa exclama de nuevo «iperro vecino malo!», a modo de corrección o reformulación.

Thémata. Revista de Filosofía №53 (2016) pp.: 237-260. 
Sr. Burns: Hola / Homer / Marge / Está deslumbrante - Ah / miren / he traído unas milhojas de maíz (el perro salta sobre Burns y lo tumba en el suelo)

Homer: ¡Perro malo! // Mmm / iperro vecino malo! / Déjeme que le ayude

[T2C4-2]

Cualquier mensaje construido con enunciados yuxtapuestos puede expresarse de un modo más explícito, es decir, podemos translucir las intenciones del emisor interpretadas por el espectador. Por ejemplo, en el caso anterior cuando dice «iPerro malo! // Mmm / iperro vecino malo!» la comunidad hablante entiende: «Perro malo! (acabo de darme cuenta que al reñirle al perro he asumido delante de las cámaras que es mío y por tanto que soy responsable de la caída del candidato a la presidencia), Mmm (hago tiempo para poder improvisar una respuesta válida que me justifique), iperro vecino malo!». ¿Por qué hablamos de absurdo entonces? En principio si hiciésemos una lectura literal de la intervención no encontraríamos más que la rectificación de un dato. Sin embargo, el absurdo proviene del descaro y de la falsa inocencia que tiene el protagonista al creer que las personas que le rodean aceptarán como válida la rectificación que propone. Los niveles de credulidad del argumento difieren entre el protagonista y la comunidad hablante (los espectadores).

La yuxtaposición es un mecanismo muy polivalente, es capaz de producir choques contextuales y rotura de expectativas como las comentadas en capítulos anteriores. El uso de enunciados yuxtapuestos requiere por parte del receptor tener en cuenta (porque se sabe, porque se deduce o porque se imagina) la información que maneja el emisor. En nuestro caso, analizando el corpus extraído de una serie de animación, el conocimiento necesario para interpretar satisfactoriamente los diálogos es el conjunto de datos sobre los personajes y sus relaciones (características, clichés adoptados, muletillas, roles, etc.). El siguiente ejemplo es una muestra del carácter dinámico de este tipo de construcción sintáctica. La falta de nexo y la agilidad del mensaje construyen una situación absurda de una forma naturalizada, es decir, dicho por el protagonista de un modo aparentemente dotado de sentido.

Homer: (oye zumbidos) ¡Ahh / abejas!

Marge: Parecen furiosas y africanas

Homer: De acuerdo / no os asustéis / hay repelente de sobra para mí

[T11C14 -1]

Thémata. Revista de Filosofía Nº53 (2016) pp.: 237-260. 
Si analizamos el ejemplo que acabamos de leer, en la segunda intervención del protagonista que supuestamente sirve de respuesta a su interlocutor, yuxtapone una proposición imperativa negativa y otra unimembre impersonal de existencia: «no os asustéis / hay repelente de sobra para mí». Desde un punto sintáctico la estructura es completamente normal. Sin embargo, justificar la calma de un grupo de personas alertadas por una colmena de abejas mediante la comprobación del nivel de repelente suficiente para una sola persona es absurdo. La comprobación particularizada de que esta situación es absurda la encontramos en la información enciclopédica que tiene el espectador sobre el protagonista de la serie. Homer es padre de familia de tres hijos y como tal la comunidad hablante (y por lo tanto el espectador) espera que tenga un comportamiento paternalista y defensivo para sus hijos y su mujer. Otras veces como vemos en el siguiente ejemplo, la extracción de contenidos implícitos absurdos no depende de la información que posea el espectador por los interlocutores del protagonista, sino de la malformación de un razonamiento. La yuxtaposición de dos proposiciones causa-efecto que simulan no conocer dicha relación evidencia la argumentación absurda. Se trata de una falacia post hoc, ergo propter hoc o de correlación coincidente. La estructura yuxtapuesta establece una relación de causa-efecto entre el curso y la conducción solo por el hecho de aparecer en el tiempo uno detrás del otro. En este caso, en el que se utiliza una subordinada adverbial, la linealidad del mensaje hace deducir de manera absurda al protagonista que la asistencia a un curso fue el motivo de su incapacidad al volante, en lugar de la embriaguez que le produjo la ingesta abusiva de vino. Si elimináramos el nexo con el que se inicia la intervención, tendríamos delante también un caso de incoherencia entre los dos hechos mencionados en el mensaje.

Homer: [...] Cuando asistí al curso de cómo hacer vino / ¿recuerdas que se me olvidó conducir?

[T5C22-2]

Al comenzar el artículo, describíamos la yuxtaposición como un mecanismo capaz de construir enunciados y situaciones absurdas. Realmente, la formación de mensajes a partir de enunciados adyacentes por sí sola no es suficiente, por lo que requiere de otros mecanismos, contenidos y razonamientos no explícitos en el mensaje.

Thémata. Revista de Filosofía №53 (2016) pp.: 237-260. 
Homer: [...] solo queda la pequeña Maggie // ¡Ohh! Chuletas de cerdo que pitan // Aquí dice que para perros // ella no sabe leer $(1 \mathrm{~s} \downarrow)$.

La oración «aquí dice que para perros, ella no sabe leer» incluye en un mismo discurso tres puntos de vista conversacionales. Uno es el de los fabricantes del producto, otro el de su hija (que aún es un bebé) y el tercero el del propio protagonista que decide obviar las recomendaciones del fabricante al descubrir que no va a recibir quejas. El absurdo de este tipo de situaciones se basa en la legitimación de un comportamiento irresponsable arguyendo como defensa la inconsciencia de dicha ilegitimidad. La inmediatez de las estructuras yuxtapuestas contrae el discurso hasta lo meramente simbólico, de modo que las proposiciones han sido estratégicamente elegidas.

La omisión de información implícita al oyente es quizás la característica más significativa desde el punto de vista conversacional de la yuxtaposición. En el siguiente ejemplo tenemos una muestra de argumentación absurda, un refuerzo argumentativo basado en un supuesto hiperbólico. La pausa natural y gramatical propia de la estructura yuxtapuesta sugiere la justificación de la primera proposición mediante la segunda. El protagonista plantea una situación hipotética en la que a su hijo mayor le revienta la cabeza (en este momento de la serie, calificado como alumno sobredotado intelectualmente y asistente de una escuela para genios). Las probabilidades de que a una persona le reviente la cabeza por ser inteligente es altísimamente improbable, por no decir imposible. Utilizar este supuesto hiperbólico como argumento para mimar a su segunda hija y utilizarla como seguro de vejez, es disparatado.

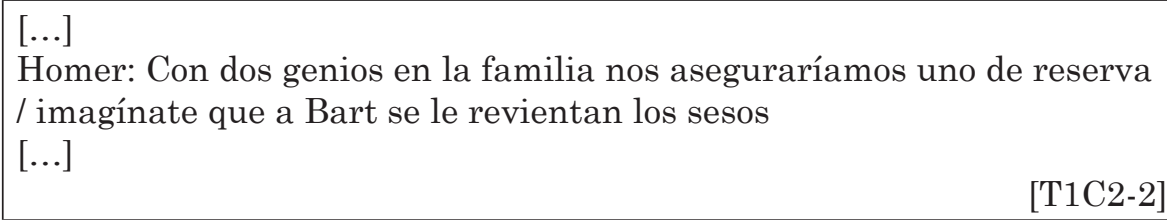

Por último, comentaremos la función espaciadora de la yuxtaposición, un espejismo sintáctico. Realmente no podemos hablar de proposiciones yuxtapuestas en el siguiente ejemplo sino más bien de adyacencia sintáctica, sin conexión alguna. Anteriormente hablábamos de la demora existente en el lenguaje oral como una característica habitual producida por la falta de planificación del discurso. En el disparatado siguiente caso el protagonista suspende la enunciación para inventar una respuesta via- 
ble que posteriormente ratifica creando una atmósfera mística en torno a su propuesta. En el siguiente ejemplo vemos al protagonista hablando con el reverendo de su iglesia, por recomendación de su esposa. El orgullo y el sentimiento de inferioridad del protagonista le llevan a contestar proponiendo una cita bíblica como réplica ante un consejo sobre la supuesta infidelidad que había cometido. La capacidad de construir una respuesta improvisada y posible a partir del conocimiento, de oídas y casual, de los sermones dominicales del reverendo supone firmar esta situación absurda con el sello propio del protagonista: el disparate injustificado. Las dos intervenciones de Homer están construidas mediante enunciados yuxtapuestos (Y yo voy a recordarle /// la de Mateo veintiuno diecisiete - Sí // ¡medite!). La segunda respuesta transmite mediante la pausa un halo místico que coincide con la cita propuesta en primer lugar por el reverendo. El absurdo lo encontramos en la interpretación de la pausa y en el cálculo que el protagonista hace para comprobar la credibilidad que él le concede.
$[\ldots]$
Reverendo: Homer voy a recordarle una cita de San Mateo / la siete veintiséis / "El hombre insensato construyó su casa sobre arena" Homer: Y yo voy a recordarle /// la de Mateo veintiuno diecisiete Reverendo: ¿"Y dejándole salió de la ciudad se fue a Betania y allí pasó la noche"? Homer: // Sí // ¡medite!

[T4C3-2]

\section{Conclusiones}

El análisis de las estructuras yuxtapuestas desde un punto de vista pragmático nos revela que conforman una herramienta versátil a la hora de crear situaciones contextualmente ricas. Los textos orales o escritos construidos con este tipo de estructuras sintácticas cumplen una doble función: ofrecer una serie de contenidos implícitos necesarios para su interpretación y dejar abierta la lectura del contenido que transmiten, al ser dependientes de la capacidad del receptor. El descubrimiento de un contexto que no dota de sentido al discurso formado por proposiciones yuxtapuestas es el gatillo dinamizador de la interpretación inferencial.

Como hemos visto a lo largo del artículo, las oraciones yuxtapuestas constituyen un mecanismo expresivo de las conexiones (implícitas) establecidas mentalmente. Funcionan como un motor semántico capaz de 
generar contenidos subyacentes al discurso, al transmitir de forma indirecta la información.

El rol que desempeña la cadencia de la entonación y las pausas (silencios) en los discursos construidos a partir de oraciones yuxtapuestas es crucial como indicador (elemento ostensivo) de información extra no revelada directamente. Además de suponer una estructuración previa del pensamiento y ser capaz de generar saltos discursivos, permiten crear discursos polifónicos que ocasionen choques contextuales y den lugar a la comunicación absurda.

$\mathrm{Al}$ establecer puentes semánticos y discursivos idóneos para generar el absurdo, pudimos aislar las principales causas que dan lugar al sinsentido a través de estas estructuras parentéticas: mezcla de ideas incongruentes, interpretación incorrecta por parte del receptor de la relación implícita en la yuxtaposición, expresión de intenciones contrarias a las expresadas por el lenguaje explícito, mediante pausas reflexivas y marcadas; generación de expectativas frustradas inmediatamente en la siguiente proposición mediante cadencia o pausas y razonamientos incorrectos usando la yuxtaposición como una relación entre premisas y conclusión. ${ }^{5}$

\section{Referencias bibliográficas}

Aitchinson, J.: Words in the mind. An introduction to the mental lexicon. Oxford-Nueva York: Basil Blackwell, 1987.

Álvarez, A. [en línea]: "Oralidad y cotidianidad" en Análisis de la oralidad: una poética del habla cotidiana, http://elies.rediris.es/elies15/ cap11.html. [Consultado: 25/05/15].

Brown, G. y Yule, G.: Teaching the spoken language. Cambridge: Cambridge University Press, 1983.

Bruneau, T. J.: "Communicative silences: forms and functions" en The journal of communication, 23, 1973, pp. 17-46.

Cestero, A. M.: Comunicación no verbal y enseñanza de lenguas extranjeras. Madrid: Arco-Libros, 1999.

Cueto, N.: Representación e inferencia. Oviedo: Universidad de Oviedo, 2002.

Grice, H. P.: "Lógica y conversación" en Valdés, L.: La búsqueda del significado. Madrid: Tecnos, 1991 [1975].

Gómez, L.: Análisis sintáctico. Teoría y práctica. Madrid: Editorial SM, 2005.

[5] La nomenclatura T3C9-1 indica la temporada (T), el capítulo (C) y el orden de la intervención extraída del capítulo referido que utilizamos del corpus confeccionado a partir de la serie de animación y el largometraje "Los Simpson".

Thémata. Revista de Filosofía №53 (2016) pp.: 237-260. 
Jaworski, A.: The power of silence. Social and pragmatic perspectives. Newbury Park: SAGE Publications, 1993.

Jensen, J. V.: "Communicative functions of silence" en ETC. Vol. XXX, 3, 1973. pp. 249-257.

Lahuerta, J. y Pujol, M.: "El lexicón mental y la enseñanza de vocabulario" en Segoviano, C. (ed.): La enseñanza del léxico español como lengua extranjera. Frankfurt-Madrid: Vervuert-Iberoamericana, 1996, pp. 117-129.

Laín, P.: "Hablar y callar" en Boletín de la Real Academia Española, Tomo LXXIV - Cuaderno CCLXIII, 1994, pp. 453-465.

Mateu, R. [en línea]: "El lugar del silencio en el proceso de comunicación" en TDR (Tesis Doctorales en Red). Universidad de Lleida, http://www.tdx.cat/handle/10803/8173]. [Consultado: 02/06/15].

Narbona, A.: "Sobre la evolución sintáctica y escritura-oralidad" en Actas del V Congreso Internacional de Historia de la Lengua Española. Vol. 1. Madrid: Gredos-CAM, 2000, pp. 133-158.

Narbona, A.: "Diálogo literario y escritura(lidad)-oralidad" en Eberenz, R. (ed.): Diálogo y oralidad en la narrativa hispánica moderna. Perspectivas literarias. Madrid: Verbum, 2001, pp. 189-208.

Poyatos, F.: La comunicación no verbal, Vol 1: Cultura, lenguaje y conversación. Madrid: Istmo, 1994.

Rivas, A.: "Que dicimos cando non falamos? O silencio na comunicación” en Madrygal, 12, 2009, pp. 99-107.

Saville-Troike, M.: "The place of silence in an integrated Theory of communication" En Tannen, D. y Saville-Troike, M.: Perspectives on silence. Norwood: Alex Publishing Corporation, 1985, pp. 3-18.

Sperber, D. y Wilson, D.: Relevance: communication and cognition. (versión original) La relevancia: comunicación y procesos cognitivos. Madrid: Visor, 1986. 
